\title{
Redução de Ácidos Graxos Saturados em Spreads de Chocolate
}

\author{
João Paulo Ribeiro Boemer*, Kamila F. Chaves, Ana Paula Badan Ribeiro
}

\section{Resumo}

Os spreads são cremes de chocolate espalháveis, composto basicamente de óleo de palma, açúcar, cacau em pó e lecitina de soja. No contexto da crescente preocupação com o consumo excessivo de gorduras saturadas, a tecnologia de organogéis vêm como uma alternativa viável para a obtenção de gorduras semissólidas com redução do conteúdo de ácidos graxos saturados e com propriedades compatíveis à aplicação em alimentos. Este projeto tem como objetivo estudar a substituição total da fase lipídica convencional de spreads de chocolate por organogéis à base de óleo de girassol alto oleico, estruturados por diferentes agentes estruturantes, empregados a altos teores (6\%). Com isso, foram desenvolvidas e analisadas difrentes formulações de spreads, caracterizando-os quanto às suas propriedades físicas e estabilidade.

Palavras-chave: Spread, organogél, ácidos graxos.

\section{Introdução}

A aplicação de organogéis vem sendo estudada há alguns anos e inclui o uso de estruturantes para compor óleos comestíveis, reduzindo a necessidade de ácidos graxos saturados nas formulações e para minimizar a migração de óleo líquido nos alimentos, como os spreads. ${ }^{12}$

Os spreads são cremes de chocolate que podem ser consumidos puros ou como ingredientes de outras preparações. Devido ao alto teor de óleos e gorduras (aproximadamente $30 \%$ de conteúdo lipídico), os spreads são caracterizados como um sistema gorduroso contínuo, fazendo com que as propriedades da gordura possuam efeito significativo na qualidade $e$ características sensoriais do produto. ${ }^{3}$

Este estudo tem como objetivo a substituição total da gordura convencional de spreads de chocolate utilizando a tecnologia de organogéis, reduzindo o teor de ácidos graxos saturados no produto e aumentando, assim, a saudabilidade dos mesmos. Para isso, foram criadas e analisadas 30 formulações diferentes, com o intuito de obter um spread com as características ideais, sendo elas: espalhabilidade a temperatura ambiente, resistência às alterações de temperatura durante o armazenamento, não exsudação de óleo no produto e manutenção das características sensoriais e organolépticas dos spreads convencionais, como maciez e cremosidade.

\section{Resultados e Discussão}

Os spreads estudados possuíam a mesma composição base: açúcar refinado, cacau em pó alcalino, óleo e lecitina de soja e aroma de chocolate. As variações das formulações foram à respeito da composição da sua fase lipídica (óleo de palma ou organogél), apresentadas na Tabela 1, sendo que alguns também tiveram acréscimo de leite em pó.

A Tabela 2 apresenta os resultados dos testes feitos no Texturômetro - Probe cônico (45ํ), sendo que S1 corresponde ao spread feito com a fase lipídica F1 apresentada na Tabela 1, assim respectivamente.
Tabela 1. Formulações das fases lipídicas dos spreads de chocolate.

\begin{tabular}{|c|c|c|c|c|}
\hline Ingrediente & $\mathrm{F} 1(\%)$ & $\mathrm{F} 2(\%)$ & $\mathrm{F} 3(\%)$ & $\mathrm{F} 4(\%)$ \\
\hline Óleo de palma & 99,60 & - & - & - \\
\hline $\begin{array}{c}\text { Oleo de girassol } \\
\text { oleico }\end{array}$ & - & 97,00 & 97,00 & 97,00 \\
\hline Cera de candelilla & - & 1,00 & 1,00 & - \\
\hline $\begin{array}{c}\text { Hardfat de óleo de } \\
\text { palma }\end{array}$ & - & - & 1,00 & 1,00 \\
\hline Monoglicerídeo & - & 1,00 & - & 1,00 \\
\hline $\begin{array}{c}\text { Monoestearato de } \\
\text { sorbitana }\end{array}$ & - & 1,00 & 1,00 & 1,00 \\
\hline Lecitina de soja & 0,40 & - & - & - \\
\hline
\end{tabular}

Tabela 2. Texturômetro - Probe cônico (45ํ)

\begin{tabular}{|c|c|c|c|c|}
\hline Teste & S1 $(\mathrm{g})$ & S2 $(\mathrm{g})$ & S3 $(\mathrm{g})$ & S4 $(\mathrm{g})$ \\
\hline 1 & 594,5 & 16,4 & 12,3 & 11,3 \\
\hline 2 & 445,2 & 18,1 & 13,9 & 17,1 \\
\hline 3 & 855,1 & 16,2 & 16 & 17,1 \\
\hline Média & 631,6 & 16,9 & 14 & 15,2 \\
\hline
\end{tabular}

Cada formulação apresentou características diferentes em relação à consistência, espalhabilidade e tamanho da partícula.

\section{Conclusões}

As formulações que apresentaram melhores características de consistência e espalhabilidade e textura foram as S4 e S3, que correspondem a spreads produzidos com organogél F4 e F3, respectivamente.

Porém, em relação ao tamanho de partículas foram as S4 (organogél F4) e S3 (organogél F3)

No geral, portanto, o spread que apresentou melhores resultados sensoriais, ou seja, o que mais se aproximou das características do spread convencional (com óleo de palma) foram os spreads com organogéis à base de óleo de girassol oleico sem uso de cera de candelilla.

${ }^{1}$ HUGHES, P. A et al. Post-inflammatory colonic afferent sensitisation: differen subtypes, different pathways and different time courses. Gut, v. 58, n. 10, p. 1333-1341, 2009.

2 ROGERS, M. A.; WRIGHT, A. J.; MARANGONI, A. G. Nanostructuring fiber morphology and solvent inclusions in 12-hydroxystearic acid / canola oil organogels. Current Opinion in Colloid \& Interface Science, v. 14, n. 1, p. 33-42, fev. 2009.

${ }^{3}$ NORBERG, S. Chocolate and confectionery fats. In: Modifying lipids for use in food. [s.1.] Woodhead Publishing Limited, 2006. v. 53p. 1689-1699. 